\title{
Trade and Welfare Implications of Networks
}

\author{
Alan V. Deardorff \\ The University of Michigan
}

Paper prepared for the Murray S. Johnson

Conference on International Economics,

University of Texas,

April 28-29, 2001

March 4, 2001 


\title{
ABSTRACT \\ Trade and Welfare Implications of Networks
}

\author{
Alan V. Deardorff \\ The University of Michigan
}

This paper ...

Keywords: Word1

\section{Correspondence:}

Word2

JEL Subject Code: F1 Trade

F11 Neoclassical Trade Models

Alan V. Deardorff

Department of Economics

University of Michigan

F12 Model with Imperf Comp.

F13 Commercial Pol.

F2 Factor Movements

Ann Arbor, MI 48109-1220

Tel. 734-764-6817

Fax. 734-763-9181

E-mail: alandear@umich.ed

http://www.econ.lsa.umich.edu/ alandear/ 
March 4, 2001

\title{
Trade and Welfare Implications of Networks*
}

\author{
Alan V. Deardorff \\ The University of Michigan
}

\section{Introduction}

Recent research has begun to explore the roles of business and social networks in international trade. Rauch (1999) has surveyed much of that literature, as well as contributing importantly to it himself in a number of other papers. The message of this work is that these networks matter for trade. The incentive for trade no doubt lies in the international differences in relative costs that have preoccupied trade theory since Ricardo, but to respond to these incentives requires effort and knowledge of their existence. It therefore matters "who you know." Firms that have connections in other countries, formal or informal, are better placed to learn about trading opportunities and to take advantage of them. Therefore, networks can play an important role in determining which firms and which countries succeed in penetrating a particular foreign market.

To the best of my knowledge, this literature has focused, understandably, on making the case that networks exist and that they do indeed matter. In this paper, I will take their existence and importance as given, and move on to ask some of the other questions that trade theorists routinely ask about phenomena that are newly identified: What effects do networks have on the welfare of particular countries and of the world as a

\footnotetext{
* I have obviously benefited from reading the work of Jim Rauch in preparing this paper. I am also indebted to Peter Debaere for prompting me to explore these issues.
} 
whole? And granted that networks can stimulate trade along particular routes and in particular industries, how may this matter more broadly for international patterns of trade? In particular, is it possible that network effects could undermine the law of comparative advantage, causing trade to flow in directions that traditional trade theory would view as perverse?

To address these questions, I will simplify - probably oversimplify - the network literature by focusing on what strikes me as its more important feature for these purposes: that networks reduce the costs of trade. If international trade could take place as freely and easily as we often assume in our theoretical models, then there would be no place for networks. If a small difference in price of a good between two countries led automatically to a sufficient flow of the good from the low-price to the high-price country so as to equalize their prices, then the opportunities for trade would be gone before a network could exploit them. And the same would be true even if there were transportation costs that would prevent the full equalization of prices. For networks to play any role at all, then, it must be the case that there are other costs associated with this process, costs that prevent prices from converging to the level of observable transport costs. What these trade costs are is important for some purposes, no doubt, but not for others. For my purposes here, it is enough to know that networks work by reducing these costs.

What my paper is about, then, is really the implications of reductions in trade costs. To the extent that this does indeed capture an important feature of networks, then what I say is applicable to networks as well. But the results are also more general, 
applying to reductions in trade costs - including transport costs, if you like - regardless of the source of those reductions.

It is therefore somewhat surprising to me that these questions have not already been answered, or at least they have not been answered in literature that I am aware of. I will no doubt get, and will welcome, direction to the works of others that have addressed these issues. But as far as I know right now, trade theorists have paid remarkably little attention to trade costs and to changes in them. It is true that they are a bit messy to deal with, which may account for this neglect. But I think the more important reason is that we have not thought them to be important. Economics has often taken its lead from the field of mechanics, within physics, where great success was achieved by assuming away friction as an unimportant complication. We have done the same with trade costs.

But recent evidence suggests that this may have been a mistake. The world does not trade nearly as much as our models say that it should if there were no costs to trade. Focusing on the factor content of trade, Trefler (1995) noted this with his Mystery of the Missing Trade. Obstfeld and Rogoff (2000) point to possible trade costs to explain all of their "Six Puzzles." And if trade costs are substantial, then we need to understand their role, not just in explaining such mysteries and puzzles, but in the more mundane task of exploring how they matter for things like the patterns of trade and the gains from trade that we thought we understood from our frictionless models.

There are really just two such questions that I will address in this paper: First, what are the welfare implications of a drop in trade costs? Can the world lose? Can particular countries lose? And if so, which countries, and under what circumstances? Second, how do trade costs, or changes in them, matter for trade patterns? Does the Law 
of Comparative Advantage still hold in their presence? And can trade costs cause particular goods to be exported that would otherwise have been imported, or vice versa?

For both of these purposes, I will be most interested in changes in trade costs that do not occur across the board, for example to a country's trade with all of its potential trading partners. Motivated by the role of networks in reducing trade costs, I will be particularly interested in trade costs that are reduced only over particular trading routes, such as between a pair of countries that acquire a common population through migration.

\section{Welfare Implications}

Can a fall in trade costs reduce welfare? In general, of course, anything is possible, so the answer to this must be yes. But a more instructive answer might identify conditions under which the answer is no, plus particular departures from those conditions that make it yes. That is what I will examine here.

I suspect that no one would doubt, for example, that if trade costs exist on all trade flows, and if these costs were to be reduced by the same proportion on all of these flows, then this would be beneficial for the world. This is true, as I will show below, and it closely resembles a result due to Bruno (1972) from tariff theory: a proportional reduction in all ad valorem tariffs is welfare improving. It also suggests that a nonproportional reduction in trade costs could reduce welfare. Indeed, we know that this is true of tariffs, where a preferential tariff reduction such as in a free trade area can reduce welfare due to its possible trade diverting effects. Can the same be true of trade costs?

In the conclusion of his paper, Rauch (1999) conjectures that it can, and says that "a transnational network can have an effect analogous to harmful trade diversion if it 
links the 'wrong' countries." However, the analogy may be misplaced. Trade diversion due to a preferential tariff reduction lowers welfare because the reduced tariff induces buyers to substitute toward a good that truly costs more than what they bought before, and only seems to cost less because it is subject to a lower tariff. But if trade costs fall on imports from one country and not another, such substitution is toward goods that really do cost less, once one takes into account the real costs of accomplishing the trade. It is not obvious, therefore, that reduced trade costs (due to a network or any other cause) with a trading partner whose production costs are high can be welfare worsening. And I will argue next that, under otherwise ideal conditions, they will not be. The key is that trade costs are real costs, using up real resources, whereas tariffs are not. Tariffs therefore distort behavior by artificially altering the price signals that guide behavior. But trade costs enter into prices in ways that should guide behavior, since the costs are real.

I would argue that in an undistorted world economy, any meaningful reduction in real trade costs will increase world welfare. By meaningful, I mean a reduction that actually matters, in that it changes any behavior, thus excluding only those reductions that leave welfare unchanged. The argument is simple. Because real trade costs use real resources, a reduction in these costs permits the world economy to do exactly what it did before and have some resources left over. A competitive economy will then use these released resources to produce more, yielding a world output that is worth more, at the new equilibrium prices, than the outputs previously produced. With a suitable redistribution of this income, every consumer can be made capable of consuming what they did before, while some consumer or consumers can get more. Thus world welfare is increased. 
Note that, as always in the welfare propositions of trade theory, this one assumes costless redistribution of income. World welfare is defined as increasing, here, only if the gainers could compensate the losers and remain better off, and thus we must allow for such potential income redistribution. It is not the case, as I will discuss below, that a reduction in trade costs necessarily benefits everybody in the absence of such redistribution.

To make the argument slightly more formally, consider an ideal world in which perfectly competitive producers of $G$ goods in $C$ countries produce and trade these goods with consumers in these countries. There are no tariffs or other artificial barriers to this trade, but the trade itself may be costly in that it uses real resources. To capture this, I define $X_{g c i}$ as the quantity of good $g$ delivered by country $c$ to country $i$, or collected at country $i$ if negative. Thus the $X_{g c i}$ include both domestic production $(i=c)$, exports $(i \neq c$, $\left.X_{g c i}>0\right)$, and imports $\left(i \neq c, X_{g c i}<0\right)$. I let each country have a production set, $F_{c}=\left\{X_{g c i}, g=1, \ldots, G ; i=1, \ldots, C\right\}$, that incorporates $b o t h$ the usual constraints of production technology and factor endowments, plus also the constraints of the resources needed for trade itself. Of these sets, I assume only that they are (weakly) convex, and that trade costs are nonnegative, in the sense that ${ }^{1}$

$$
\begin{aligned}
& X^{0} \in F_{c} \Rightarrow X^{1} \in F_{c} \\
& \text { where } X_{g c c}^{1}=X_{g c c}^{0}+\sum_{i \neq c} X_{g c i}^{0}
\end{aligned}
$$

\footnotetext{
${ }^{1}$ See Deardorff (1980).
} 


$$
X_{g c i}^{1}=0, \quad i \neq c
$$

A competitive equilibrium in this world economy will consist of a matrix of prices, $p^{e}=\left\{p_{g c}^{e}\right\}$, of each good in each country, and matrices of output and trade, $X_{c}^{e}=\left\{X_{g c i}^{e}\right\}$, such that the goods are both supplied and demanded. On the supply side, we need only that the activities chosen (production and trade) maximize their value at these prices:

$$
\sum_{g} \sum_{i} p_{g i}^{e} X_{g c i}^{e} \geq \sum_{g} \sum_{i} p_{g i}^{e} X_{g c i} \quad \forall X_{c} \in F_{c}, c=1, \ldots, C
$$

On the demand side, this same bundle of goods must be demanded at these prices and at incomes that are earned from production. In order to allow for the income redistribution that will be needed later, let $Y_{c}$ be income of country $c$ and require only that world income, $Y_{w}^{e}$ be earned:

$$
Y_{w}^{e}=\sum_{c} Y_{c}^{e}=\sum_{c} \sum_{g} \sum_{i} p_{g i}^{e} X_{g c i}^{e}
$$

Letting preferences be represented by demand functions $D_{c}(p, Y)$, equilibrium therefore requires that

$$
D_{g c}\left(p_{1 c}^{e}, . ., p_{G c}^{e}, Y_{c}^{e}\right)=D_{g c}^{e}=\sum_{i} X_{g i c}^{e}, \text { for } g=1, \ldots, G ; c=1, \ldots, C
$$

Now suppose that we start from an initial equilibrium, $e 1$, with an initial technology, and then technology changes to capture reduced real costs of trade. This will appear as an expansion of one or more of the production sets, $F_{c}$, to become $F_{c}$ '. Since 
everything that was possible before is still possible, it must be true that the new sets contain the old ones:

$$
F_{c}{ }^{\prime} \subset F_{c} \text {, for } c=1, \ldots, C \text {. }
$$

Consider any new equilibrium, $e 2$. Since (2.2) must hold for this new equilibrium, and since the original quantities were elements of $F_{c}$ and therefore, by (2.5), of $F_{c}$, , it follows that

$$
\sum_{g} \sum_{i} p_{g i}^{e 2} X_{g c i}^{e 2} \geq \sum_{g} \sum_{i} p_{g i}^{e 2} X_{g c i}^{e 1} \quad, \text { for } c=1, \ldots, C
$$

Summing over all countries, $c$, this tells us that world income in the new equilibrium is at least large enough for world consumers to purchase the same goods that they did before, and assuming that the expansion of the production sets was "meaningful," as defined above, income will be more than enough for this purpose. That is,

$$
Y_{w}^{e 2}>\sum_{g} \sum_{c} p_{g c}^{e 2} D_{g c}^{e 1}
$$

Thus it is possible for world income to be distributed such that each country can afford the same goods that it consumed in the old equilibrium and some country can afford more. Therefore the world has gained from this reduction in trade costs, in the same sense that the world gains from trade.

Redistribution is necessary, here, because there is no guarantee that each country will gain without it. This is not because of trade diversion, but because of terms-of-trade 
effects. It is easy to construct an example when a single country loses from a fall in trade costs, but its loss is more than made up for by a larger gain to someone else.

For example, suppose that one country is the world's sole supplier of an essential and tradable good, the only substitute for which is a second good that is extremely costly to transport and that is produced in abundance but only by a second country. If the cost of transporting this second good were to fall, the price of the first good would also fall and the first country would suffer a worsening of its terms of trade. Of course, the world as a whole would benefit from the cheaper availability of both goods, and the second country would benefit especially from its new access to the world market. But the first country would lose. Thus individual countries can certainly lose from a fall in trade costs, even though the world as a whole must gain, even when there are no distortions.

Furthermore, if there are distortions, then even the world may lose from a fall in trade costs, for reasons that should be familiar from the theory of the second best. For example, suppose that trade costs fall for a good that is already oversupplied, from a social perspective, due to a global negative externality associated with its production. Then the expansion in its output that will occur when trade costs fall will worsen that externality, and the costs of this may outweigh the benefits found above.

\section{Trade Implications}

A fall in trade costs, due to networks or any other source, and especially a fall that affects only some trade flows and not others, can easily alter the pattern of trade. In Deardorff (1979) I showed how sensitive trade patterns could be to tariffs, either when goods are used as intermediate inputs into production or when trade involves multiple 
countries. In either case, a change in a tariff can cause a good that was imported by a country to become exported and another good that was exported to become imported. Real trade costs are different from tariffs, as noted above, but in this respect they are the same. All that was needed for those reversals of trade patterns was that tariffs drive a wedge between domestic and foreign prices, and real trade costs do this as well as tariffs. Therefore, we know immediately that changing trade costs, whatever their cause, can potentially alter not just the size but even the direction of trade flows.

For example, suppose the United States has a comparative advantage in agriculture, and an even stronger comparative advantage in assembling cars, but a comparative disadvantage in producing the steel it needs as input to making cars. If the cost of transporting steel is too large for it to be traded, the U.S may be uncompetitive in producing cars and find itself importing them, paying for them with exports of agricultural products. But if the cost of transporting steel goes down sufficiently for it to import steel, then it will export cars instead, perhaps even importing agricultural products as well as steel.

Or, in an example involving networks, suppose that Indonesia has an abundance of timber, and also a comparative advantage in turning logs into plywood and other processed forms. But it lacks the knowledge of developed country markets to enable it to move its processed goods to market. It therefore exports only logs, in spite of its seeming comparative advantage, because the cost, for it, of trading plywood is too high. But now if a community of Indonesian emigrants establishes itself in some developed country, that community may provide the connections needed to facilitate this trade, and Indonesia will be able to export the processed good. Depending on the extent of its resources of both 
timber and labor, these connections may ultimately lead it to switch from exporting to importing logs in order to serve its processing industry.

These examples may suggest that comparative advantage no longer plays a role in determining trade, once trade costs are involved. But that is not the case. All of these examples fit within the framework of a general model of comparative advantage, for which I showed in Deardorff (1980) that the Law of Comparative Advantage holds in the weak form of various correlations. That is, while it is indeed true that the direction of trade of any particular good may be sensitive to trade costs (both real and artificial), it is also true that, on average across all goods, net trade is positively correlated with comparative advantage. This is true both for individual countries relative to the world and for the world as a whole.

Of course, the Law of Comparative Advantage in this form is extremely weak, telling us very little about what to expect of a country's trade. It is far from vacuous, essentially cutting in half the number of possibilities that one may see in the world, but that is far less than we might hope for from a theory of trade. ${ }^{2}$ To finish this discussion, therefore, I would like to suggest a somewhat more useful interpretation that I have been working on recently, within which trade costs and therefore networks could play an important explanatory role.

The idea is that a country's trade depends not so much on its comparative advantage relative to the world as a whole (except under perfectly free and frictionless trade), but rather on its comparative advantage relative to the countries that are "closest"

\footnotetext{
2 The Law cuts possibilities in half, in the sense that it rules out all vectors of trade that would yield correlations of the wrong sign. While this may not sound like much, this is really all that a two-good, twocountry model does also: of the two possible trade patterns, it rules out one.
} 
to it in the sense of having the lowest trade costs. If trade costs happen to depend only on geographical distance, and if they are large, then comparative advantage will be a local phenomenon, each country's trade pattern depending on its comparative advantages relative to its nearest neighbors. If and as trade costs come down over time, we can expect trade patterns to change, as the relevant measure of comparative advantage broadens to include ever more distant countries.

Of course, one of the messages of the network literature is that trade costs may not depend just on distance, but also on the connections that happen to exist between even distant countries that share significant cross-border networks. For a theory of local comparative advantage to make sense, it may be necessary to treat such networkconnected trading partners as neighbors, even though they are geographically remote.

I will illustrate the role of trade costs in comparative advantage with two examples. The first illustrates the point just made that when trade costs are high it is local, not global comparative advantage that matters. And the second shows how something that lowers trade costs between a pair of countries can alter local comparative advantage.

To keep things simple, both examples use a partial equilibrium model of trade in which each of several countries, $c=1, \ldots, C$, each provides a net supply of a good that depends on its price, $p_{c}$, relative to their autarky price, $a_{c}$, as follows:

$$
S_{c}\left(p_{c}\right)=p_{c}-a_{c}
$$


If trade were free and frictionless, then equilibrium in this model would consist of a single world price, $p_{w}$, prevailing in every country, such that the world market would clear:

$$
\sum_{c} S_{c}\left(p_{w}\right)=\sum_{c}\left(p_{w}-a_{c}\right)=C p_{w}-\sum_{c} a_{c}=0
$$

Thus the world price is just the simple average of the autarky prices, $p_{w}=\bar{a}=\sum_{c} a_{c} / C$, and each country exports or imports the good depending on whether its own autarky price is below or above this average. This, in a sense, is global comparative advantage at work, to the extent that one can make such a statement in a partial equilibrium model.

Now suppose that these countries are arranged geographically around a circle, along which any trade must flow, with the cost of trading this good proportional to distance along the circle. Then for any cost of trade per unit distance, we can work out what the prices in each country must be, and the trade (if any) between them, in order to clear the markets. Letting $d_{i j}$ be the distance along the circle between countries $i$ and $j$, and letting $t$ be the cost of trading a unit of the good one unit of this distance, then equilibrium consists of prices $p_{c}^{e}$ in each country and quantities of exports $x_{i j}$ from country $i$ to country $j$ such that each country's net supply equals its exports minus its imports

$$
S_{c}\left(p_{c}^{e}\right)=p_{c}^{e}-a_{c}=\sum_{i} x_{c i}-\sum_{i} x_{i c}
$$

and also that prices differ in adjacent countries by at most the trade cost between them, equaling that trade cost if trade actually takes place: 


$$
\left.\begin{array}{l}
x_{i j}\left[\left(p_{j}^{e}-p_{i}^{e}\right)-t d_{i j}\right]=0 \\
x_{i j} \geq 0 \\
\left(p_{j}^{e}-p_{i}^{e}\right) \leq t d_{i j}
\end{array}\right\} \quad \text { for all } i, j=1, \ldots, C
$$

\section{Example 1:}

My two examples, within this framework, both include four countries, with considerable symmetry to make them easy to follow. The parameters of the first example are shown in Figure 1, where four countries, $A, B, C$, and $D$ are arranged around a circle (not shown) at the distances indicated. Their autarky prices for the good, $a_{c}$, are also shown.

From a global perspective, countries $A$ and $B$ have the lower autarky prices than $C$ and $D$, and therefore comparative advantage in the good. If trade were free and frictionless, the world price would be 25 , and $A$ and $B$ both would export it. However, countries $A$ and $B$ are much closer to each other than they are to countries $C$ and $D$, and compared to their closer neighbors the comparative advantages of $A$ and $C$ are different than they are globally. $A$ has a local comparative disadvantage in this good, while $C$ has a local comparative advantage. Indeed, if we try different values for the unit trade cost, $t$, we see that both local and global comparative advantage matter at different levels for this trade cost. Table 1 shows the relevant variables for several arbitrary values of the trade cost.

If the cost of trade, $t$, is 10 or more per unit, then there is no trade, since the differences between adjacent autarky prices are everywhere at least this large. When the trade cost drops to 8 , then trade between neighbors $A$ and $B$ becomes possible, since the trade cost is 8 and the autarky price difference is 10 . Trade also occurs between $C$ and $D$, 
for the same reason, but not between the two groups of countries. Because of the larger difference between the groups (4), the cost of trade is 32 , which is too large to be overcome. Instead, each country's price adjusts towards that of its neighbor and they trade with each other. As the trade cost falls still further, to 6, this local trade increases and trade between the groups remains zero.

However, when the trade cost reaches 5 (not shown in the table), the cost of trading across groups becomes equal to their price difference (between $A$ and $D$, for example), and from there on, trade between the groups becomes possible. The next stop in Table 1 is $t=4$, at which the cost of trading between $A$ and $D$, for example, (16) become less than the price difference that would exist between them if they did not trade (20). As a result, the two together become net exporters of the good, pulling its price up in $A$ and $B$ and down in $C$ and $D$. At this point too, the pattern of bilateral trade becomes indeterminate, since the excess supply from country $B$ can equally well travel clockwise through $A$ or counterclockwise through $C$ to reach the excess demand in $D$. This indeterminacy is reflected in the ranges of values shown for the bilateral exports in the last four columns of Table 1 .

As the trade cost continues to fall toward zero, the prices in, say, $A$ and $B$, not only come together, but they also rise absolutely since it becomes increasingly possible for the two countries both to be net suppliers to countries $C$ and $D$. And of course, when the trade cost reaches zero, then we have a single world price of 25 , as explained above.

The important message from this example is how sensitive trade patterns can be to trade costs. Country $A$ is a net importer of the good when trade costs are relatively high, but becomes a net exporter when they are low, and country $C$ does the reverse. 
Correspondingly, as the trade cost falls monotonically, the prices in these two countries change, first in one direction and then the other.

Does this mean that comparative advantage is not working? Hardly. The overall correlation of trade with comparative advantage holds throughout, but the correlation leaves open a great many possible trade patterns that are consistent with it, and we are seeing different ones of them arise as trade costs fall. Also, the gains from trade are present throughout this exercise, and in fact become larger - worldwide - as trade costs fall. What the example shows, then, is not a failure of comparative advantage but rather a refinement, in which a slightly more precise definition of comparative advantage, relative to the trading partners that are accessible with given trade costs, determines more fully the pattern of trade.

\section{Example 2:}

My second example appears in Figure 2 and Table 2. Here again I have four countries arranged at various intervals around a circular world, but I have altered the autarky prices to suit my needs. In particular, the patterns of local and global comparative advantage are now the same, with countries $B$ and $C$ both having lower autarky prices for the good than both their neighbors and than the ultimate world single-market price (which in this case is 47.5). My purpose here is to show how the trade pattern can change if trade cost falls substantially over a particular route, perhaps due to a network forming between two countries that facilitates trade. In my example, I reduce the trade costs only between countries $A$ and $D$, and I reduce them to zero by the expedient of changing the "distance" between them from 4 to zero. 
The results appear in Table 2. In the initial equilibrium I set the trade cost at 20, large enough that countries trade only with their close neighbors. That is, country $A$ imports the good from its neighbor, $B$, while country $D$ likewise imports from $C$. There is no trade between the more distant groups.

Now the trade cost between $A$ and $D$ disappears. Price in $A$ and $D$ must therefore be the same, and it turns out that equilibrium is found at a price in both of 55 , which is higher than the autarky price in $A$. Thus country $A$, due to this (network-facilitated) drop in trade costs has become a net exporter of the good, rather than the net importer that it was before. It is an even larger gross exporter, since country $B$ exports even more than before, all of which flows through country $A$ and on to $D$. As it happens, price in $D$ falls enough that exports from $C$ are no longer viable. Therefore another effect of this drop in trade costs along one trade route is that another country drops out of trade altogether.

At the start of this paper I noted the concern expressed by Rauch (1999) that falling trade costs between certain pairs of countries could have "trade diverting" effects, and this is exactly what has happened here. Furthermore, country $D$ 's imports have been diverted from a lower cost supplier $C$ (autarky price 45) to a higher cost supplier $A$ (autarky price 50). How then can it not be that the world has suffered a loss?

The answer, of course, is that to buy from $C$, country $D$ must incur the additional real cost of 20 per unit imported, while to buy from $A$ it does not. And unlike a tariff, this is a cost in real resources somewhere, not a transfer to someone else or its own government. Just as a check that I have not contradicted the welfare result of the previous section, Table 3 shows the welfare effects on each of the four countries - and therefore 
the world as a whole - of this reduction in trade costs, calculated from the usual changes in producer/consumer surplus.

The calculation confirms that the world as a whole gains substantially from this fall in trade costs, even though it may seem to have "distorted" the pattern of trade. Not surprisingly, countries $B$ and $D$ gain substantially from the change, since they were the countries with the most extreme comparative advantage and disadvantage to be exploited by trade. Also not surprisingly, country $C$ is hurt, for the change has deprived it completely of the gains from trade in this product.

What may be surprising, however, is that country $A$, which one may have thought of as initiating the change by creating a network, happens to lose. The network permitted it to switch from importing the good to exporting it, and a mercantilist would be confident that this makes it better off. But in fact, when this happens its gives up all the gains from trade that it had as an importer, and since in this example it only exports a smaller quantity than it previously imported, the new gains from exporting are outweighed by the lost gains from importing. Of course there is no reason to think that this is a generally likely result, but it points to an outcome that could be quite unexpected.

\section{Conclusion}

My conclusion from this is twofold. First, at least if I am correct in my interpretation of networks being primarily about ways of reducing costs of trade, then we do not need to worry (if anybody ever did) that the presence of networks may undermine what we thought we knew about trade. And, whether we knew it or not, the overall effect of reducing trade costs due to networks (or any other cause) is likely to be beneficial for 
the world as a whole. I say "likely," rather than "sure to be," only because there is always the possibility in an imperfect world that distortions will interact with trade costs in a way that could undermine this result. But in general, the presence of unknown and (therefore?) random distortions should not be expected to interfere with this result or any other proposition from trade theory.

However, the presence of networks also draws our attention to the likely fact that the total costs of trade are much larger than just more obvious costs of transportation. Theory tells us that trade costs can matter a great deal for patterns of trade as well as for the gains from trade of individual countries. It is therefore important that we learn as much as we can about what trade costs are and about how they may be affected by networks and other aspects of the trading environment. 


\section{References}

Bruno, Michael 1972 “Market Distortions and Gradual Reform," Review of Economic Studies 39 (July), pp. 373-383.

Deardorff, Alan V. 1980 "The General Validity of the Law of Comparative Advantage," Journal of Political Economy 88, (October), pp. 941-957.

Obstfeld, Maurice and Kenneth Rogoff 2000 "The Six Major Puzzles in International Macroeconomics: Is There a Common Cause?” NBER Macroeconomics Annual 2000.

Rauch, James E. 1999 “Business and Social Networks in International Trade,” Journal of Economic Literature, forthcoming.

Trefler, Daniel 1995 "The Case of the Missing Trade and Other Mysteries," American Economic Review 85, (December), pp. 1029-1046. 
Table 1

Prices and trade for various trade costs, $t$, in Example 1

\begin{tabular}{|c|c|c|c|c|c|c|c|c|c|c|c|c|}
\hline \multirow{2}{*}{$t$} & \multicolumn{2}{|c|}{$A$} & \multicolumn{2}{|c|}{$B$} & \multicolumn{2}{c|}{$C$} & \multicolumn{2}{c|}{$D$} & $x_{A B}$ & $x_{B C}$ & $x_{C D}$ & $x_{D A}$ \\
\cline { 2 - 15 } & $p_{A}$ & $S_{A}$ & $p_{B}$ & $S_{B}$ & $p_{C}$ & $S_{C}$ & $p_{D}$ & $S_{D}$ & $\left(-x_{B A}\right)$ & $\left(-x_{C B}\right)$ & $\left(-x_{D C}\right)$ & $\left(-x_{A D}\right)$ \\
\hline 10 & 20 & 0 & 10 & 0 & 30 & 0 & 40 & 0 & 0 & 0 & 0 & 0 \\
\hline 8 & 19 & -1 & 11 & 1 & 31 & 1 & 39 & -1 & -1 & 0 & 1 & 0 \\
\hline 6 & 18 & -2 & 12 & 2 & 32 & 2 & 38 & -2 & -2 & 0 & 2 & 0 \\
\hline 4 & 19 & -1 & 15 & 5 & 31 & 1 & 35 & -5 & $-1,-5$ & 4,0 & 5,1 & $0,-4$ \\
\hline 2 & 22 & 2 & 20 & 10 & 28 & -2 & 30 & -10 & $0,-8$ & 10,2 & 8,0 & $-2,-10$ \\
\hline 0 & 25 & 5 & 25 & 15 & 25 & -5 & 25 & -15 & $0,-10$ & 15,5 & 10,0 & $-5,-15$ \\
\hline
\end{tabular}

Table 2

Prices and trade in Example 2, with trade cost $t=20$ and varying "distance" between $A$ and $D$.

\begin{tabular}{|c|c|c|c|c|c|c|c|c|c|c|c|c|}
\hline & \multicolumn{2}{|c|}{$A$} & \multicolumn{2}{|c|}{$B$} & \multicolumn{2}{c|}{$C$} & \multicolumn{2}{|c|}{$D$} & $x_{A B}$ & $x_{B C}$ & $x_{C D}$ & $x_{D A}$ \\
$\left(d_{A D}\right.$ & $p_{A}$ & $S_{A}$ & $p_{B}$ & $S_{B}$ & $p_{C}$ & $S_{C}$ & $p_{D}$ & $S_{D}$ & $\left(-x_{B A}\right)$ & $\left(-x_{C B}\right)$ & $\left(-x_{D C}\right)$ & $\left(-x_{A D}\right)$ \\
\hline 4 & 40 & -10 & 20 & 10 & 55 & 10 & 75 & -10 & -10 & 0 & 10 & 0 \\
\hline 0 & 55 & 5 & 35 & 25 & 45 & 0 & 55 & -30 & -25 & 0 & 0 & -30 \\
\hline
\end{tabular}

Table 3

Welfare effects of reducing "distance" $d_{A D}$ from 4 to 0 in Example 2.

$\begin{array}{rr}\text { Country } A & -37.5 \\ \text { Country } B & +262.5 \\ \text { Country } C & -50 \\ \text { Country } D & +400 \\ \text { World } & +575\end{array}$




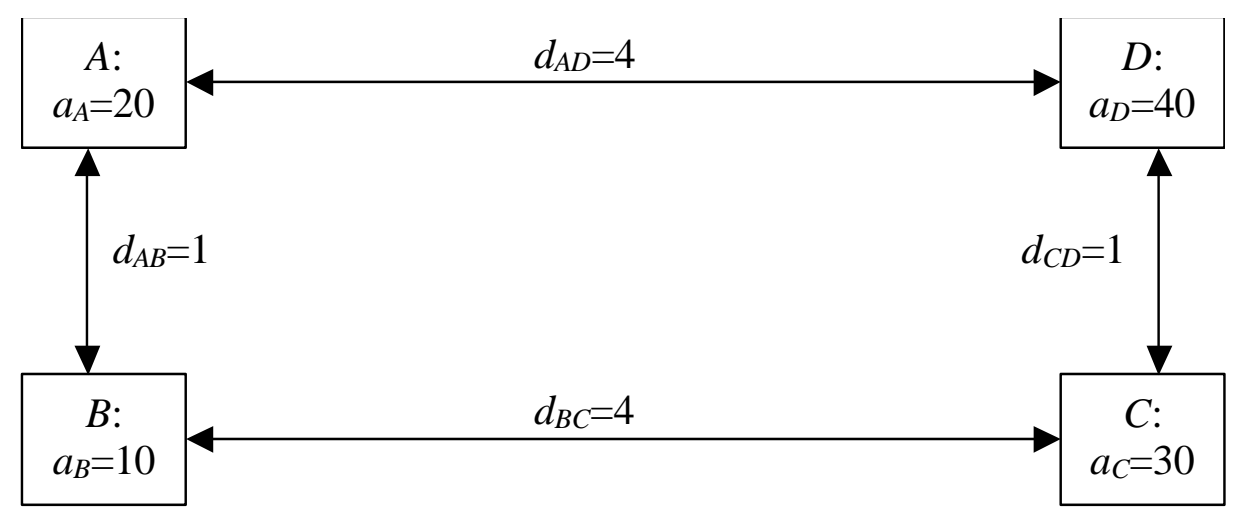

Figure 1

Example 1: Four countries, local and global comparative advantage disagree

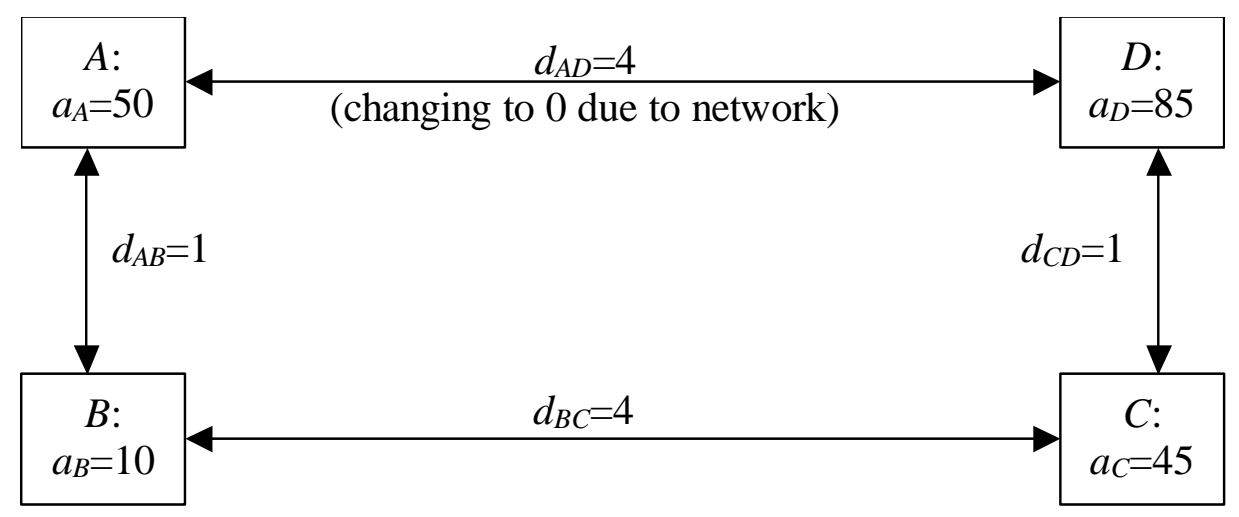

Figure 2

Example 2: Four countries, local and global comparative advantage agree 